\title{
ANÁLISE ESTRUTURAL DAS ARQUIBANCADAS DO ESTÁDIO MANOEL LEONARDO NOGUEIRA
}

\author{
Bezerra, Eric M. F. \\ Professor \\ Universidade Federal de Campina Grande \\ Paraíba; Brasil \\ eric_mateusjes@hotmail.com \\ Pinto, Jesse W. G. \\ Engenheiro \\ Universidade Federal Rural do Semi-Árido \\ Rio Grande do Norte; Brasil \\ jessewillemanutd@hotmail.com
}

\author{
Nunes, Valmiro Q. G. \\ Professor \\ Universidade Federal Rural do Semi-Árido \\ Rio Grande do Norte; Brasil \\ valmiro@ufersa.edu.br \\ Andrade, Paula N. \\ Professor \\ Centro Universitário Christus \\ Ceará; Brasil \\ paulanobreandrade@gmail.com
}

\section{RESUMO}

O presente trabalho trata da análise estrutural das arquibancadas do Estádio Manoel Leonardo Nogueira por meio de uma simulação computacional baseada no Método dos Elementos Finitos (MEF), de modo a corroborar, bem como ampliar, as informações relativas ao real comportamento estrutural do estádio. Para tanto, foi realizada uma análise elástica-linear, com auxílio do software SAP2000, com intuito de determinar os esforços atuantes e os respectivos deslocamentos do sistema de pórticos que sustentam as arquibancadas, visto que estes são os responsáveis pelo desempenho dinâmico-funcional das mesmas. Feito isso, pôde-se comparar a armadura calculada nas seções críticas dos elementos, segundo os critérios estabelecidos pela NBR 6118 (ABNT, 2014), com as armaduras aferidas in loco, para identificar se as anomalias estruturais presentes no estádio foram decorrentes ou agravadas pelo dimensionamento estrutural. Verificou-se que os pórticos de sustentação das arquibancadas se encontram em um nível elevado de degradação e a intervenção para recuperação e reforço estrutural é urgente. O trabalho propõe, portanto, além de um parecer acerca da estabilidade dos pórticos, dados que permitem embasar um estudo futuro com finalidade de evitar a ruína do estádio, visto que a análise estrutural é o primeiro passo para tal.

Palavras-chave: Estádio Nogueirão, Análise estrutural, SAP2000.

\section{ABSTRACT}

This paper presents a structural analysis of the bleachers of Manoel Leonardo Nogueira Stadium by means of a computer simulation based on Finite Element Method (FEM), to corroborate and to increase the informations related to the real structural behavior of the stadium. Hence, an elastic-linear analysis assisted by the software SAP2000 was carried out, in order to determine the active forces and the respective displacements of the system of portals that support the bleachers, since these are the ones responsible for their dynamic-functional performance. In this way, the calculated reinforcement steel could be compared in the critical sections of the elements, according to the criteria established by NBR 6118 (ABNT, 2014), with the reinforcement steel measured on site, to identify if the structural anomalies present in stadium were due or aggravated by structural design. It has been found that the support frames of the bleachers are at a high level of degradation. Therefore, an intervention for recovery and structural reinforcement is essential. This paper proposes an opinion on the stability of the portals and data which allow to motivate a future study with the purpose of avoiding the ruin of the stadium, since the structural analysis is the first step for such.

Keywords: Nogueirão Stadium, Structural analysis, SAP2000.

\section{INSTRUÇÕES GERAIS}

Inerentemente ao crescimento vertiginoso de admiradores do futebol, que é o grande destaque esportivo e um dos maiores meios de entretenimento nacional, exigiu-se a construção de estádios que acomodassem adequadamente grandes quantidades de pessoas com conforto e segurança. Ao passar dos anos, os estádios se tornaram grandes monumentos, dados como verdadeiras obras de arte permeadas por grande teor tecnológico, que correlacionam estética 
e funcionalidade estrutural. Alguns destes se tornam grandes cartões postais das suas cidades, como, por exemplo, o estádio Maracanã, que é um dos maiores pontos turístico do Rio de Janeiro.

O Estádio Manoel Leonardo Nogueira (Figura 1-a), popularmente conhecido como "Nogueirão", possui vastas conotações sociais, econômicas e políticas na cidade de Mossoró. Inaugurado em 1967, este é o segundo maior estádio do Rio Grande do Norte, com capacidade de 9.000 pessoas, sendo utilizado em competições estaduais, regionais e nacionais da CBF (Confederação Brasileira de Futebol) (MENDONÇA, 2014). O mesmo representa mais do que um patrimônio público de importância esportiva, uma vez que expressa também um significado cultural e histórico para a cidade. Entretanto, mesmo com a sua representatividade, as estruturas que sustentam as arquibancadas se encontram em avançado estado de deterioração (Figura 1-b), de tal forma que parte significativa dela foi interditada. Concatenando a interdição parcial pela perda da estabilidade das estruturas com as condições inapropriadas das instalações de combate a incêndio, hoje, a capacidade do estádio foi reduzida à 3.500 pessoas.

a)

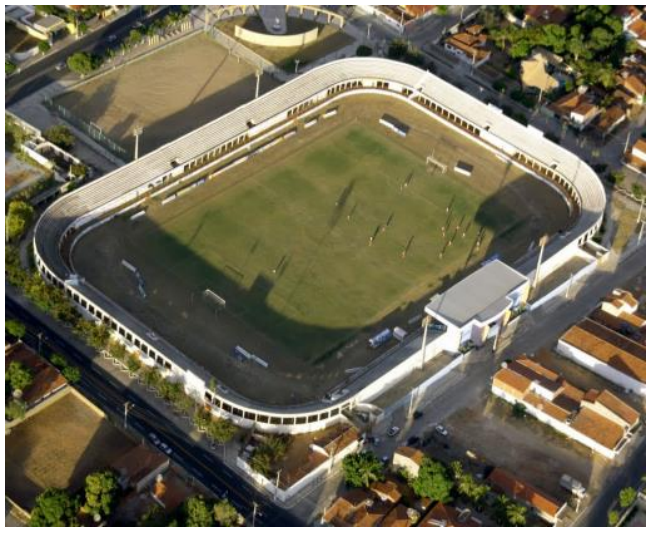

b)

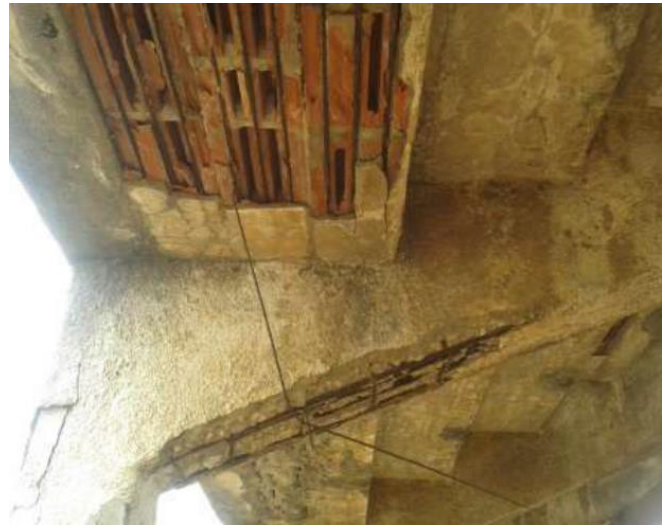

Figura 1: a) Foto aérea do estádio e b) estado da região interditada das arquibancadas

Muito se tem falado do perigoso estado em que o estádio se encontra, sem que se detenha ao seu verdadeiro significado. O cenário atual do Nogueirão é preocupante, o que reflete um verdadeiro descaso dos órgãos competentes, mesmo sob demasiados apelos da população local. O estádio já foi utilizado em competições estaduais e em competições nacionais da CBF, sediando jogos do Campeonato Potiguar, da Copa do Nordeste, da Copa do Brasil e do Campeonato Brasileiro das séries C e D (Figura 2). Em função do avançado estado de degradação das estruturas, o sinistro do estádio é iminente e requer soluções imediatas, fato que justifica a iniciativa de estudos relacionados a este.
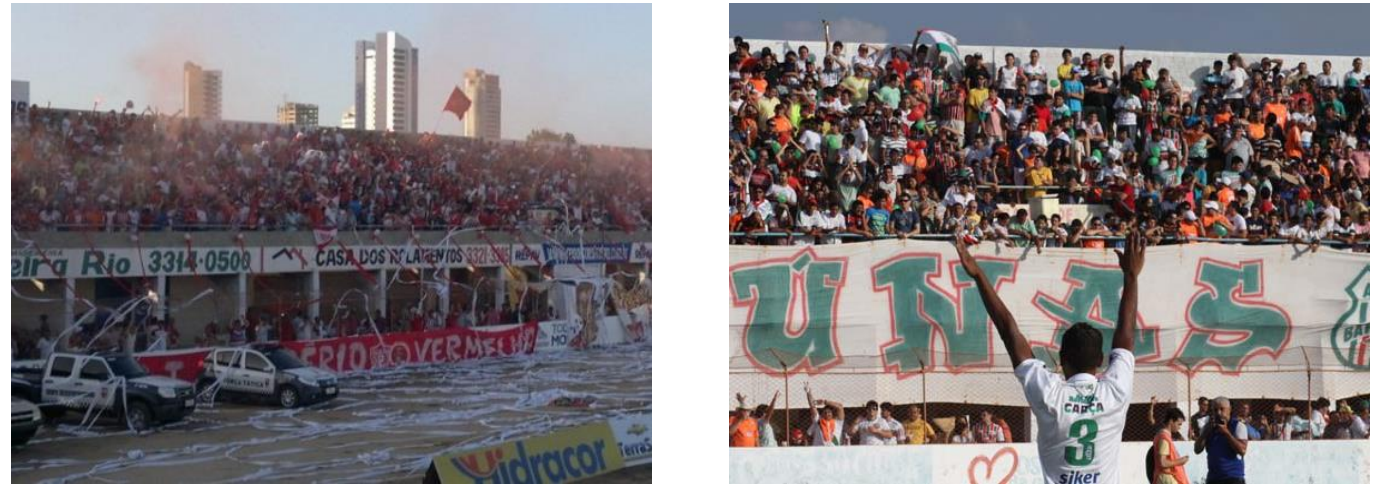

Figura 2: Nogueirão lotado em jogos do Potiguar e do Baraúnas

A falta de documentos técnicos referentes à concepção e cálculo do estádio, bem como de outros monumentos históricos, dificultam a análise dos mesmos. Sendo assim, faz-se necessário, sobretudo, o incentivo de estudos de edificações com uma abordagem focada nos aspectos estruturais, já que, em muitos casos, não se tem registros técnicos dos patrimônios históricos da cidade de Mossoró. A escassez de estudos de monumentos históricos está presente em todo país, já que a nossa cultura não fomenta tal ação.

A análise estrutural, de acordo com Kimura (2018), é a principal etapa do projeto de estruturas, uma vez que é a partir dos seus resultados que se dimensiona e detalha os elementos para atender as condições exigíveis para segurança e um 
bom desempenho em serviço. É nesta etapa em que se define um modelo matemático (modelo estrutural) capaz de estimar a resposta da estrutura ante às ações que lhe foram aplicadas. Essa resposta pode ser expressa em termos de tensões, deformações, esforços internos e deslocamentos.

O trabalho trata, portanto, da análise estrutural dos pórticos das arquibancadas do Estádio Manoel Leonardo Nogueira, com intuito de verificar o comportamento estrutural e motivar a iniciativa de estudos que sirvam de base para evitar um possível sinistro deste patrimônio histórico de inestimável importância para a cidade de Mossoró. Para tanto, foi feita uma análise linear por meio da modelagem dos pórticos espaciais através do software SAP2000 (Structural Analysis Program), que é um dos softwares de análise estrutural baseado no Método dos Elementos Finitos (MEF) mais difundidos no mundo. Com os esforços obtidos nessa etapa, é feito o dimensionamento das armaduras para uma seção e seus valores são comparados com os aferidos in loco, para, assim, verificar se há relação entre as avarias eclodidas com o dimensionamento estrutural.

Em função da ausência do projeto estrutural, o levantamento das armaduras foi realizado através de uma intervenção destrutiva dos elementos estruturai situados na região interditada do estádio, com remoção do cobrimento de concreto. A ausência do projeto estrutural obrigou a adoção de hipóteses acerca das características do concreto e inviabilizou uma análise mais precisa.

\section{ESTRUTURA DO ESTÁDIO}

A estrutura do estádio é formada por uma série de pórticos em concreto armado, interligados por vigas de travamento, possuindo, no total, 184 vigas principais e 560 pilares. Os degraus da arquibancada eram formados por blocos cerâmicos com armadura na parte inferior e um capeamento de concreto. No entanto, parte das arquibancadas foram demolidas e reconstruídas em concreto armado no ano de 2005, em um esboço de uma reforma realizada pela Prefeitura Municipal de Mossoró.

A reforma contemplou apenas os degraus. Os pórticos que os apoiam não foram recuperados nem reforçados. Além disso, foi inserida uma estrutura metálica de cobertura na área das cadeiras numeradas e a alvenaria utilizada como guarda corpo nas bordas das arquibancadas foram elevadas, o que provocou um acréscimo de cargas nas estruturas existentes.

As arquibancadas são divididas em setores, aqui denominados de módulos (Figura 3). No total, são 10 módulos que dividem a estrutura radialmente através de juntas de dilatação.

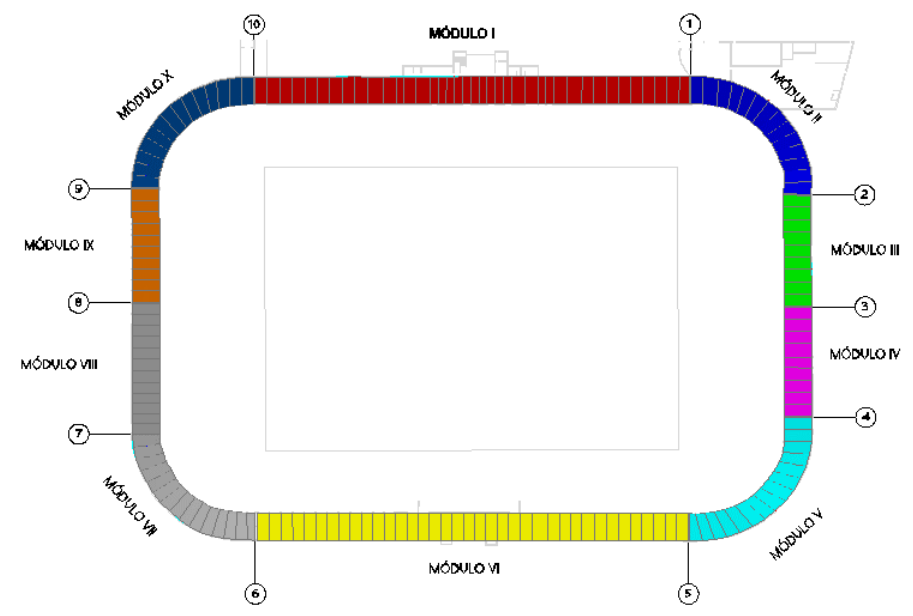

Figura 3: Planta dos setores do estádio

Tendo em vista que os módulos da estrutura são independentes, foi escolhido o módulo III na obtenção do modelo de elementos finitos usado no estudo. O mesmo pertence ao setor noroeste e é composto por 10 pórticos paralelos, espaçados entre si com distância média de $3,30 \mathrm{~m}$. Válido se faz salientar que os módulos V, VI e VII estão interditados. 
A escolha do módulo III para análise não tem nenhum motivo particular, uma vez que os módulos possuem uma similaridade arquitetônica, o que permite, portanto, uma simulação média do comportamento de todos os setores através da análise de apenas um deles. A Figura 4 mostra a elevação do pórtico.

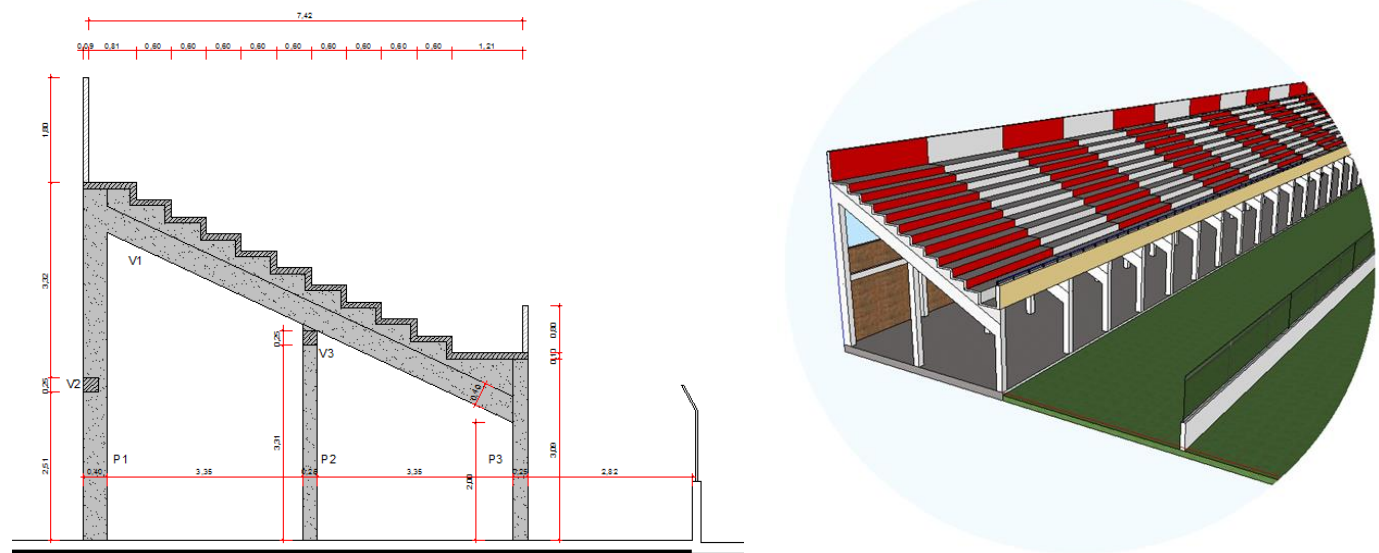

Figura 4: Elevação do pórtico analisado

Os pórticos de sustentação das arquibancadas possuem, cada, três pilares e uma viga inclinada principal, onde se apoiam os degraus. Além das vigas principais, duas vigas ligam os pórticos, servido, como elemento de travamento e para reduzir o comprimento de flambagem dos pilares. O pilar mais alto (P1) tem seção $25 \mathrm{~cm}$ x $40 \mathrm{~cm}$, estando o maior comprimento na direção da viga inclinada. Esta última, V1, possui a mesma seção de P1. Os demais pilares, P2 e P3, bem como as demais vigas, V2 e V3, tem seção $25 \mathrm{~cm}$ x $25 \mathrm{~cm}$.

\section{MODELO COMPUTACIONAL}

Conforme fora supracitado, o modelo foi concebido na plataforma do programa SAP2000, versão 15.0.0. Segundo Lima (2013), o mesmo se trata de uma ferramenta computacional extremamente potente que oferece diversos recursos para análise estática e dinâmica, linear e não-linear, análise dinâmica com sismos, análise de ponte com trens-tipo, inclusão de não-linearidade geométrica e considerações de fluência e retração pelo método dos elementos finitos, o que possibilita simulações de estruturas de maneira bastante satisfatória.

Pela natureza do problema analisado neste trabalho, a análise realizada será linear elástica. De acordo com Fontes (2005), esta análise é normalmente empregada na verificação do estado limite de serviço, sendo utilizada na verificação do estado limite último quando se pode garantir a ductilidade dos elementos estruturais. O mesmo autor acrescenta que esse é o tipo de análise mais utilizada, dada sua simplicidade de aplicação e pelo fato do conhecimento referente já estar bem consolidado.

Para simular as vigas e pilares, foram utilizados elementos do tipo frame. Esse é o tipo de elemento usado pelo SAP2000 para modelagem de elementos lineares. O mesmo foi desenvolvido com a formulação tridimensional de viga/coluna, em que são representados os efeitos de flexão biaxial, torção, deformação axial e deformação por cisalhamento biaxial (COMPUTERS AND STRUCTURES, 2013). Sua representação é feita mediante a informação dos seus dois nós extremos, contendo cada um destes 6 graus de liberdade (translação na direção dos três eixos e rotação em torno destes). Feito isso, o usuário deve informar as características da seção e as propriedades do material. O programa inclui ainda uma série de perfis de aço catalogados, embora permita a customização da seção.

As lajes foram modeladas como elemento do tipo shell. Esse tipo de elemento é utilizado para modelagem de elementos planos, podendo ser de 3 (elemento triangular) ou 4 nós, possuindo cada nó, assim como no elemento frame, 6 graus de liberdade. Sua formulação combina comportamento de membrana (mambrane) e de placa (plate), podendo ser usada para a modelagem de placas, chapas e cascas. É possível usar o elemento shell para trabalhar puramente como membrana, puramente como placa, ou das duas maneiras, o que o próprio manual recomenda.

A formulação para o comportamento de membrana é isoparamétrica, incluindo componentes de rigidez translacionais no plano do elemento e rotacionais na direção normal ao mesmo. Quanto às placas, sua formulação inclui componentes 
de rigidez rotacional fora do plano do elemento e componentes de rigidez translacional na direção normal ao mesmo. $\mathrm{O}$ software utiliza como padrão a formulação de placas finas (Teoria de Kirchhoff). Pode-se, no entanto, optar por utilizar a formulação de placas espessas (Teoria de Mindlin/Reisner).

Os degraus das arquibancadas se comportam como lajes apoiadas em duas de suas bordas pelos pórticos. Dadas suas características geométricas, os degraus foram modelados como uma única laje inclinada com espessura equivalente de $10 \mathrm{~cm}$, formada por elementos finitos de cascas quadrilaterais segundo a teoria de placas finas (Shell-Thin), que negligencia, dessa maneira, o efeito do cisalhamento.

Nas bases dos pilares que compõem os pórticos estão presentes sapatas isoladas cujas dimensões são desconhecidas e a aferição inviável. Para idealização da infraestrutura no modelo, os apoios foram considerados rígidos, isto é, os nós da base dos pilares dos pórticos tiveram todos os seus graus de liberdade restritos (nós engastados).

A malha foi determinada através da identificação constância dos valores dos esforços. Foram testadas malhas com número crescente de elementos até que a diferença dos esforços de uma malha pra outra fosse pequena. Percebeu-se que nos nós do elemento, o acréscimo de elementos da malha não variou muito o resultado. No interior dos mesmos, no entanto, uma malha mais grosseira ofereceu resultados bem diferentes dos esperados, como ilustra a Figura 5.

a)

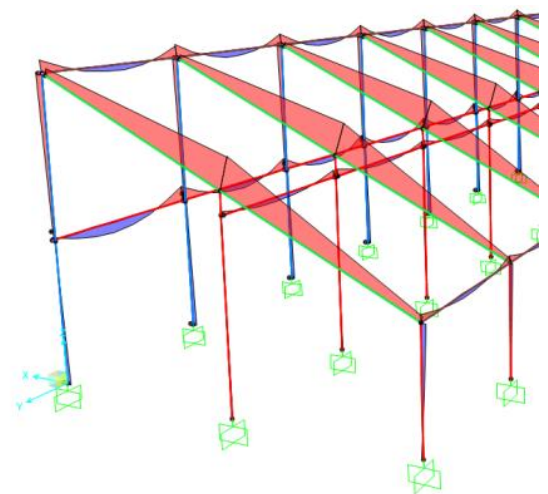

b)

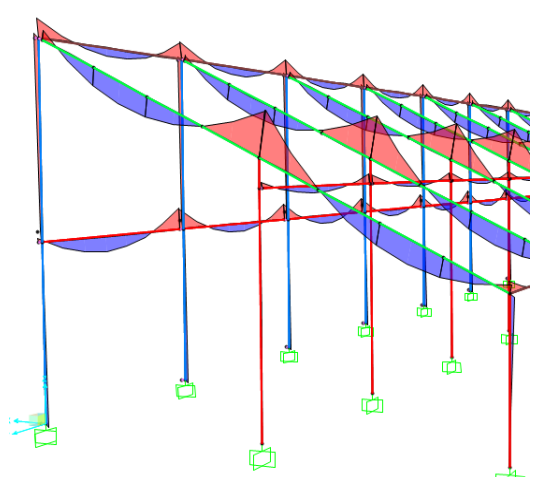

Figura 5: Diagrama de momento fletor para a) uma malha mais grosseira e b) para uma malha mais refinada

A estrutura do estádio Manoel Leonardo Nogueira é feita em concreto armado. Com a inexistência do projeto estrutural e com a impossibilidade da realização de um ensaio para determinar a resistência característica à compressão $\left(f_{c k}\right)$ da estrutura, adotou-se para esta o valor de 12,5 MPa, visto que essa era a resistência à compressão do concreto mínima, com idade de 28 dias, na época da execução do estádio (NB-1, 1940).

Foi adotado o peso específico de $25 \mathrm{kN} / \mathrm{m}^{3}$, estabelecido pela NBR 6120 (ABNT, 2019), e o coeficiente de Poisson igual a 0,2, estimado pela NBR 6118 (ABNT, 2014). O módulo de elasticidade foi estimado a partir das equações previstas na NBR 6118 (ABNT, 2014), o que resultou, para o $f_{c k}$ adotado, em um valor de aproximadamente 16 GPa.

Para simular as ações provenientes do vento, foi criado no modelo um plano vertical para receber esse carregamento, calculado com base nas prescrições da NBR 6123 (ABNT, 1988), e distribuir adequadamente na estrutura, como é feito pela alvenaria de vedação. Como o plano não existe de fato, foi criado um material cujas características fazem com que o mesmo não se comporte como um elemento estrutural, servindo apenas para transferência de cargas. Para tanto, o campo do SAP2000 destinado à inserção do peso específico nas propriedades do material foi preenchido com o valor zero, possibilitando, portanto, sua exclusão no modelo de cálculo.

\section{RESULTADOS}

\subsection{Análise estrutural}

Com base nas considerações evidenciadas na concepção do modelo, pode-se extrair os valores característicos dos momento fletores (Figura 6-a), esforços normais e cortantes, bem como seus respectivos deslocamentos (Figura 6-b). Pôde-se verificar que o pórtico mais solicitado do módulo é o pórtico 7. 
a)

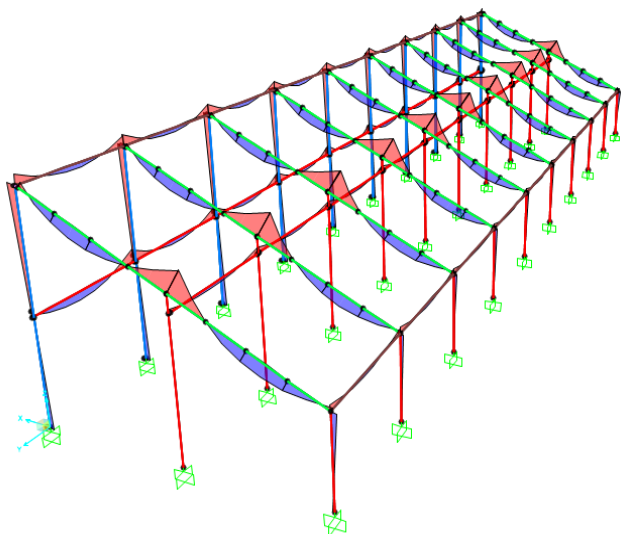

b)

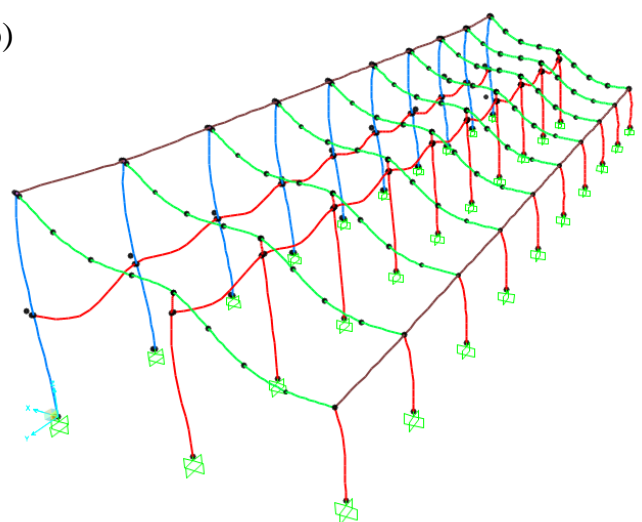

Figura 6: a) momentos fletores e b) estrutura deformada

Os valores máximos para o momento fletor do referido pórtico ocorreram na viga inclinada (V1), cujo valor máximo é de 2,31 tf.m para o momento positivo e 4,02 tf.m para o momento negativo. Nesta, atua ainda o valor máximo para o esforço cortante, com 5,44 tf. Já o esforço normal máximo ocorre na base do pilar intermediário (P2), com 12,96 tf de compressão.

Dentre as vigas de travamento, V2 é a que apresenta esforços maiores. O momento fletor máximo negativo desenvolvido nesta é de 0,29 tf.m e o positivo de 0,145 tf.m, enquanto o e esforço cortante máximo é de 0,52 tf. A Tabela 1 apresenta os valores dos esforços máximos desenvolvidos nos elementos do pórtico 7.

Tabela 1 - Esforços máximos nos elementos do pórtico 7

\begin{tabular}{|c|c|c|c|c|}
\hline \multirow{2}{*}{ Elemento } & \multicolumn{2}{|c|}{ Momento fletor } & \multirow{2}{*}{$\begin{array}{c}\text { Força } \\
\text { Cortante (tf) }\end{array}$} & \multirow{2}{*}{$\begin{array}{c}\text { Força } \\
\text { Normal (tf) }\end{array}$} \\
\hline & Positivo (tfm) & Negativo (tfm) & & \\
\hline V1 & 2,312 & 4,016 & 5,442 & 3,050 \\
\hline V2 & 0,145 & 0,290 & 0,520 & 0 \\
\hline V3 & 0,073 & 0,146 & 0,260 & 0 \\
\hline P1 & 0,708 & 1,581 & 0,509 & 7,740 \\
\hline $\mathrm{P} 2$ & 0,114 & 0,112 & 0,059 & 12,958 \\
\hline $\mathrm{P} 3$ & 0,329 & 0,898 & 0,568 & 5,406 \\
\hline
\end{tabular}

\subsection{Dimensionamento dos elementos}

De modo a analisar as armaduras dos pórticos, no que se diz respeito às dimensões utilizadas na execução em relação ao que se é recomendado, foi feito uma comparação entre as áreas de armadura verificada in loco com as calculadas sob os critérios estabelecidos pela norma vigente. Para tanto, tomou-se o dimensionamento dos elementos que compõem o pórtico 7 , sendo este usado como parâmetro por ser o mais solicitado do trecho analisado.

O dimensionamento será feito apenas para seção crítica de cada elemento, uma vez que não é possível comparar todo o detalhamento das armaduras do pórtico devido à ausência do projeto estrutural e a impossibilidade da realização de um levantamento das armaduras de toda a estrutura, sendo, portanto, inviabilizada a verificação de características tais como comprimento de ancoragem, traspasses de barras, a armadura negativa da viga inclinada que apoia os degraus, etc. Sendo assim, será feito uma comparação da armadura calculada em uma seção transversal do elemento estrutural, segundo os critérios estabelecidos pela NBR-6118 (ABNT, 2014), com a armadura cujo valor in loco foi obtido a partir da remoção do cobrimento de concreto e consequente aferição, como evidencia a Figura 7. 

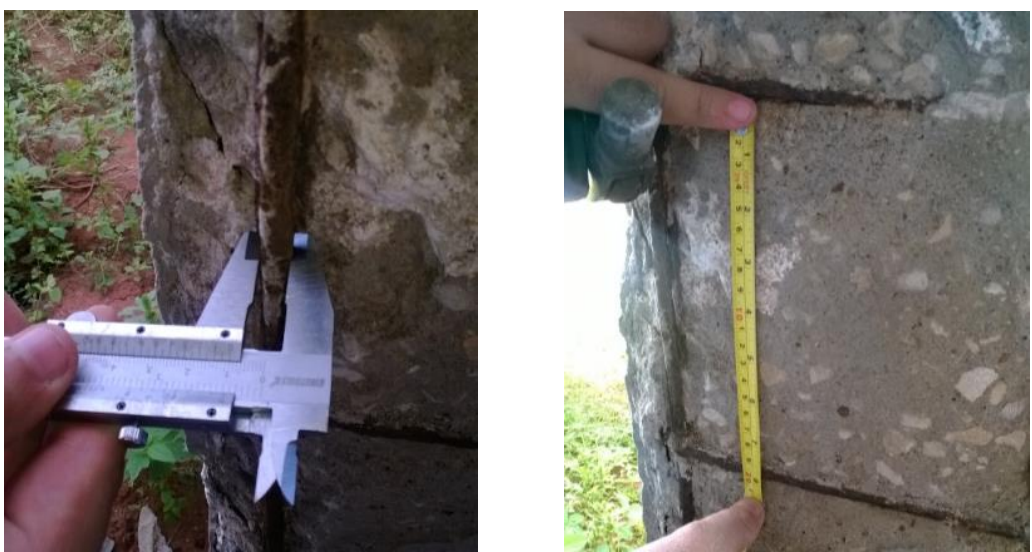

Figura 7: Aferição da armadura transversal e longitudinal

Segundo relatos do antigo engenheiro responsável pelo acompanhamento técnico do estádio, foi adotada a mesma armadura para todos os pórticos das arquibancadas e estas são constantes ao longo de cada elemento, ou seja, a mesma quantidade de barras é levada de apoio à apoio. Tal afirmação pode ser verificada em vistorias, graças à exposição das armaduras em diversos pontos do estádio, principalmente na região interditada. Tendo em vista o discorrido, embora o levantamento não tenha sido feito no pórtico analisado, pôde-se usar a armadura aferida como um padrão para as demais analisadas.

A partir dos esforços obtidos pelo SAP2000 foi feito o dimensionamento na seção crítica dos elementos estruturais para o estado limite último. Na vigas inclinada V1 $(25 \mathrm{~cm}$ x $40 \mathrm{~cm})$, que possui cobrimento de $2,5 \mathrm{~cm}$, foi feito o cálculo da armadura positiva, uma vez que não foi possível verificar a armadura negativa devido a sua consolidação com os degraus. A Tabela 2 evidencia as áreas das armaduras longitudinais calculadas para as vigas enquanto a Tabela 3 apresenta as armaduras transversais.

Tabela 2 - Armadura longitudinal das vigas

\begin{tabular}{c|c|c|c}
\hline Vigas & Aramadura calculada & Armadura aferida & Calculada / aferida (\%) \\
\hline V1 - Positivo & $3 \phi 10.0 \mathrm{~mm}$ & $5 \phi 10 \mathrm{~mm}$ & -40 \\
\hline V2 - Positivo & $2 \phi 6.3 \mathrm{~mm}$ & $2 \phi 10 \mathrm{~mm}$ & -61 \\
\hline V2 - Negativo & $2 \phi 6.3 \mathrm{~mm}$ & $2 \phi 10 \mathrm{~mm}$ & -61 \\
\hline V3 - Positivo & $2 \phi 6.3 \mathrm{~mm}$ & $2 \phi 10 \mathrm{~mm}$ & -61 \\
\hline V3 - Negativo & $2 \phi 6.3 \mathrm{~mm}$ & $2 \phi 10 \mathrm{~mm}$ & -61 \\
\hline
\end{tabular}

Tabela 3 - Armadura transversal das vigas

\begin{tabular}{c|c|c}
\hline Vigas & Aramadura calculada & Armadura aferida \\
\hline $\mathrm{V} 1$ & $\phi 5 \mathrm{~mm} \mathrm{c} / 19 \mathrm{~cm}$ & $\phi 5 \mathrm{~mm} \mathrm{c} / 15 \mathrm{~cm}$ \\
\hline $\mathrm{V} 2$ & $\phi 5 \mathrm{~mm} \mathrm{c} / 17 \mathrm{~cm}$ & $\phi 5 \mathrm{~mm} \mathrm{c} / 15 \mathrm{~cm}$ \\
\hline $\mathrm{V} 3$ & $\phi 5 \mathrm{~mm} \mathrm{c} / 15 \mathrm{~cm}$ & $\phi 5 \mathrm{~mm} \mathrm{c} / 15 \mathrm{~cm}$ \\
\hline
\end{tabular}

Nos pilares, foi feito o dimensionamento à flexão composta levando em consideração as excentricidades de $1^{\mathrm{a}}$ ordem e os efeitos de $2^{a}$ ordem. Na Tabela 4 são expostas áreas das armaduras calculadas para os pilares.

Tabela 4 - Armadura longitufinal dos pilares

\begin{tabular}{c|c|c|c}
\hline Vigas & Aramadura calculada & Armadura aferida & Calculada / aferida (\%) \\
\hline P1 & $4 \phi 12.5 \mathrm{~mm}$ & $5 \phi 10 \mathrm{~mm}$ & 0,00 \\
\hline P2 & $4 \phi 10.0 \mathrm{~mm}$ & $2 \phi 10 \mathrm{~mm}$ & $-36,4$ \\
\hline P3 & $4 \phi 10.0 \mathrm{~mm}$ & $2 \phi 10 \mathrm{~mm}$ & $-36,4$ \\
\hline
\end{tabular}

Para a armadura transversal dos pilares, foram adotados fios de $5 \mathrm{~mm}$ de diâmetro espaçados a cada $15 \mathrm{~cm}$ em P1, a cada $12 \mathrm{~cm}$ em P2 e P3. In loco, no entanto, foram verificados fios de $5 \mathrm{~mm}$ a cada $20 \mathrm{~cm}$ em todos os pilares. Nessa situação, o dimensionamento da armadura transversal se mostrou inadequado, uma vez que o espaçamento adotado foi superior ao requerido. 
Para avaliação aproximada das flechas nas vigas, foi considerado o efeito da fissuração e da fluência por meio do cálculo das flechas imediatas (pelo modelo proposto por Branson) e das flechas diferidas no tempo. Através da soma das duas, foi obtida a flecha final. Em seguida, estas foram comparadas ao limite definido pela norma, que é dado pela razão do comprimento da viga pelo valor 350 , já que se pode encaixar esta estrutura na classificação de ginásios. A Tabela 5 apresenta esses valores.

Tabela 5 - Flechas nas vigas

\begin{tabular}{c|c|c}
\hline Vigas & Flecha final $(\mathrm{mm})$ & Flecha limite $(\mathrm{mm})$ \\
\hline V1 & 3,62 & 11,38 \\
\hline V2 & 0,39 & 9,57 \\
\hline V3 & 0,23 & 9,57 \\
\hline
\end{tabular}

Atesta-se, com base nos dados supracitados, que tanto as vigas quanto os pilares do pórtico 7, nas condições estimadas, foram concebidos com excessivo conservadorismo, já que as armaduras executadas possuem valores para área de aço significativamente superiores aos calculados segundo os critérios estabelecidos pela NBR-6118 (ABNT, 2014), exceto para os estribos dos pilares, cujo espaçamento foi superior ao máximo permitido.

\section{CONCLUSÃO}

Tendo em vista os aspectos observados, foi possível inferir que a ausência de estabilidade em parte das estruturas do estádio Manoel Leonardo Nogueira não se deu em função do dimensionamento dos elementos, visto que, analisando o pórtico mais solicitado, verificou-se que a quantidade de aço utilizada é significativamente superior ao necessário e, portanto, favorável à segurança. Essa afirmação, entretanto, é comprometida pela impossibilidade de uma análise mais refinada, já que não existe documentos técnicos relativos à execução e à concepção estrutural, tais como memoriais de cálculo e descritivos e, principalmente, o projeto estrutural.

Em condições normais, utilizando-se a armadura de aço empregada, o desempenho, diante das condições de segurança global, seria satisfatório. Contudo, no presente caso, é necessário verificar até que ponto a estrutura atual pode ser completamente comprometida, de modo a atestar se a situação de todos os elementos mostra-se comprovadamente danosa para estabilidade do sistema estrutural. É necessário uma avaliação mais criteriosa, com controle tecnológico dos materiais e do grau de deterioração para definir se é pertinente o reparo ou se é necessário a demolição, parcial ou plena, dos elementos estruturais.

Supõe-se que a degradada situação atual do estádio seja atribuída à corrosão decorrente do ineficiente sistema de drenagem, da alta porosidade do concreto e do uso de cobrimento insuficiente nas armaduras, não tendo, portanto, relação alguma com o dimensionamento da estrutura. O dimensionamento conservador, atestado nesse trabalho, foi certamente o responsável por fazer com que o estádio ainda não tenha entrado em colapso.

Isto posto, não se pode furtar de ações imperiosas ante o estado em que se encontra o estádio. Sendo assim, o trato, devido ao seu reflexo e consequências, é dado como imprescindível. Nesse contexto, o trabalho apresenta um estudo que pode contribuir para evitar a ruína do mesmo, podendo, doravante, concatenar pesquisas relacionadas e, no fim, ter uma proposta completa de renovação do estádio.

A ausência dos documentos técnicos ofereceu grande dificuldade ao desenvolvimento do trabalho, uma vez que obrigou a adoção de hipóteses que minimizaram a precisão dos resultados. No entanto, estes últimos ofereceram, ainda assim, satisfatória aproximação na simulação do comportamento real da estrutura e permitiram a análise adequada do estádio. Isso se deve ao fato das considerações terem sido feitas para as condições mais desfavoráveis prováveis. Torna-se necessário, portanto, ensejar estudos relacionados ao comportamento estrutural de outros monumentos históricos, tendo em vista que a escassez de dados relacionados à estrutura destes é uma realidade comum.

\section{REFERÊNCIAS}

ASSOCIAÇÃO BRASILEIRA DE NORMAS TÉCNICAS. NB-1. Cálculo e execução de obras de concreto armado. Rio de Janeiro, 1940. 
ASSOCIAÇÃO BRASILEIRA DE NORMAS TÉCNICAS. NBR 6188: Forças devidas ao vento em edificações: Procedimento. Rio de Janeiro, 1988.

ASSOCIAÇÃO BRASILEIRA DE NORMAS TÉCNICAS. NBR 6118: Projeto de estruturas de concreto: Procedimento. Rio de Janeiro, 2014.

ASSOCIAÇÃO BRASILEIRA DE NORMAS TÉCNICAS. NBR 6120: Ações para o cálculo de estruturas de edificações. Rio de Janeiro, 2019.

FONTES, F. F. Análise estrutural de elementos lineares segundo a NBR 6118:2003. 2005. Dissertação (Mestrado) Universidade de São Paulo. São Carlos, SP, Brasil, 2005.

KIMURA, A. Informática Aplicada em Estruturas de Concreto Armado: cálculo de edifícios com o uso de sistemas computacionais. $2^{\mathrm{a}}$ ed. São Paulo: Pini, 2018.

LIMA, G. V. F. Análise dinâmica via método dos elementos finitos do estádio nacional de Brasília. 2013. Dissertação (Mestrado) - Universidade de Brasília. Brasília, DF, Brasil, 2013.

MANUAL SAP 2000. Computers and Structures Inc., Berkeley, California, USA, 2013.

MENDONÇA, J. A. F. de. A estrutura do estádio Manoel Leonardo Nogueira: histórico de projeto, execução, intervenções e estratégias para manutenção. Monografia (Graduação) - Universidade Federal Rural do Semi-Árido. Mossoró, RN, Brasil, 2014. 